\title{
1. Reimagining contemporary regulatory principle - fragmented regulatory space
}

\section{INTRODUCTION}

From a North World perspective we believe that the economic suffering of the South is an inevitable consequence of the absent or failed regulatory state. This book endorses the more organic position that when economic interests and market frames no longer serve essential social needs then state or no state, the regulatory agenda (in principle, relationships and outcomes) is toxic for sustainable social bonding. The challenge is to design a regulatory thinking for a global future beyond exponential economic growth and individual wealth creation that is crucial in a fast-approaching age after materialism, modernism and regulatory myopia.

An early motivation for this project was, in an applied sense, to identify the alternative regulatory cultures in the South World that might assist in understanding the possible social location of economy without the regulatory state. Despair surrounding the prevailing global economic model attends disillusionment with global economic regulation as the North World descends further into financial crisis, and the South suffers livelihood consequences far from its own making. Whether North or South, and across the divide, we live in fragmented regulatory space.

A better understanding about the problematic future of global regulation lies in revealing the different reasons for fragmentation within and between very different regulatory spaces. For a start in this regard, the chapter will suggest a nexus between social embeddedness, mechanical/ organic regulatory form and differential culturally located values, all of which influence essential social bonding. ${ }^{1}$ Where the analysis advances the embeddedness debate is through revealing the forces at work for and

1 In our other work we employ a device that advances such a causal consideration in order to break free of any obligatory comparative reference to consolidated states and to explore in regulatory environments where social bonds 
against social bonding, which then profoundly impact both the sustainability of regulation and of what it regulates.

Previously we have suggested that the motivations for human satisfaction are forcibly shifting from wealth creation to sustainability, creating an economic and social epoch within which analysts can more effectively make vibrant critiques of regulatory principle - recognizing the significance of transition in principle brought about by valuing conditions of social bonding and solidarity, and vice versa. ${ }^{2}$ To enrich this analysis, the chapter suggests looking for different ways of regulating that relate to essential cultural location rather than being bound to phases of state development. In so doing, we ask whether a method which goes beyond a structural approach to regulatory difference enables an acceptance of alternative fundamental phenomena that influence regulatory challenges, options and outcomes (such as concepts of fairness, the significance of efficiency, the importance of loyalty for bonding central social units).

Judging from the current debate in international relations theory, we live in a period of 'transformation' and 'transition' ... it is advisable to use the concept of transformation ... in which modern society is understood both as a result of market expansion, and as the self-protection of society against the disruptive and destabilizing effects of the market. ${ }^{3}$

Like it or not (and we don't), the development of arguments in favour of repositioning regulatory principle quickly lead to a recognition of the largely economic conditions and existing institutional constructions which stand in its way. That principles should critically inform regulation for our analysis is a given, ${ }^{4}$ even when proponents of regulation see principle and self-interest as compatible. That regulation should operate in a principled environment or even produce principled outcomes is more contestable. Braithwaite (2005), using the comparative case-study of tax evasion, proposes that markets can be flipped from the vice of tax avoidance to markets in the virtue of tax integrity. ${ }^{5}$ It is a bold theoretical assertion in keeping with the thesis that the right sort of regulation can better achieve the right economic model for thinking about the variety of human exchanges which take place. For us it is not so much the nature of the proposed transition that assists our argument, but rather that a

are deeply embedded, what counterbalances state disaggregation. See Findlay and Lim (forthcoming).

2 Findlay (2013).

3 Hettne (2006).

4 Grabosky (2012).

5 Braithwaite (2005). 
fundamental transition can occur when the essential social bonds from which the market originates are reformed to correspond with the spirit of regulation.

The analysis of regulatory principle as a means for repositioning regulatory discourse and thereby in turn enabling a fundamental shift in regulatory principle will, we argue as this book progresses, achieve its purposes in two ways. The first is to return to forms of sustainable principled regulation that we see in the societies and cultures where social bonding remains organic (see chapter 6), which are not trumped by profit maximization. Initially for the purposes of our analysis, principled regulation will be considered as an organic ${ }^{6}$ phenomenon, required to seek its essence in social embeddedness (elaborated upon in chapter 4). ${ }^{7}$ This distinction is not to suggest that valid and even valued regulatory principle may not be a mechanical and externally imposed influence over regulation. However, our interest in the transition of regulatory principle is away from the more mechanical North World frames, concentrating instead on principle which flourishes in more organic contexts of embeddedness and social bonding. The danger here, as some might consider is well exhibited in Trobriand anthropology, ${ }^{8}$ is presenting a pastoral or naïve reflection of subsistence societies wherein it is assumed that primitive market arrangements better reflect and support valuable social bonding. Armed with this warning we restrict our cultural reflection to conditions of sustainability stimulated by the very real recognition North or South that global crises are largely premised on the consistent devaluation of sustainable lifestyles. In chapter 3 we detail the 'downsides' of more organically bonded societies (and even the problems associated with a simplified organic/mechanical duality when addressing social bonds). In particular, in chapter 6 in the context of sustainable market/society synthesis, we investigate the dangers associated with 'knowledge deficit' commonly apparent in subsistence and transitional societies where organic social bonds allow for dependency and restrictive

6 The distinction between organic and mechanical regulation draws from Durkheim's analysis of mechanical solidarity and Weber's communal solidarity; see Durkheim (1893); Weber (1947).

7 For a discussion of social embeddedness in the context of the history of criminal liability and penality as regulators, see Melossi, Sozzo and Sparks (2011).

8 The cultures of the Trobriand Islands some might say have been disproportionately influential in social anthropologies celebrating tribal social embeddedness. The lives of these islanders have become emblematic of antimarket economy cultures; see for example Polanyi (1944), chapter 4. 
structures of obligation. If the market supports, but makes reliant, social bonding, then dependent sustainability arrangements can be as problematic as the resilience of the market frame.

In market situations specifically, a transformation in regulatory principle will contemplate new expectations about what we want to regulate economies for. As the values of global society are currently inevitably shifting from wealth creation (regenerative and sustainable ${ }^{9}$ or otherwise) to resource sustainability, ${ }^{10}$ the economic new deal speaks in terms of social responsibility ahead of individual profit, ${ }^{11}$ determining the most appropriate reasoning behind global regulation as a high order normative task on which, we argue, the nature of global governance may depend. ${ }^{12}$ This determination will be assisted by, the chapter asserts, examining motivations for regulation emerging out of social and cultural settings in which modernization may not be a dominant motivation. In a later section we explore, as examples of culturally located principles, some approaches to social cohesion which are culturally independent of materialist mechanics.

The second approach to contesting contemporary global regulatory motivation is to redirect the what for question. The analysis to follow will suggest a mechanical process of global ordering benefitting from embeddedness impulses, in which regulation will play a key role, and from which critical connections can be drawn between socio-economic regulatory principles and sustainable regulatory outcomes. To assist in this progression, the book moves through two opposing case-studies that exemplify either:

- organic social bonding and the promise of sustainability as an alternative regulatory principle to redirect regulatory perspectives from the South to the North Worlds; or

- mechanical bonding in transitional economies where market prioritization and dis-embeddedness hold the promise of eventually devaluing the economy and returning it to less materialist social conditions, but not without disorder and dysfunction.

Reimagining regulatory principle requires even a cursory survey of the novel normative social and economic values, besides wealth creation and

\footnotetext{
9 United Nations General Assembly (1987).

10 Anon (1999).

11 Borzaga and Becchetti (2010).

12 Findlay (2013a).
} 
exponential growth, which provide social cement in cultures and communities not recent products of neo-conservative or neo-liberal political mechanics. ${ }^{13}$ This chapter will assert that in modernized, materialist economies, perpetual economic growth and expanding production in pursuit of maximum private profit as motivators for, and evaluators of, good regulation can now be (and should be) challenged. Here again, the South/North repositioning offers the chance to disconnect regional and global regulation from its economic obsessiveness.

The timing of this book is fortuitous. Recent global financial upheaval has relieved us of the struggle to justify regulation as valuable and viable for socializing healthy market conditions. Social disorder, as a consequence of dis-embedded labour markets, even in repressive societies, is on the rise (see chapter 5). Contemporary possibilities for our wider critique of prevailing regulatory principle (or lack of it) have been afforded to critical scholars and policy makers by the cracks appearing in the Washington Consensus assault on commercial regulation, and the not unconnected emerging interest in regulatory contexts beyond the North World. ${ }^{14}$

\section{CONTEXTS FOR THE ANALYSIS}

In order to confirm our analytical platform there is a need to empirically research the anthropology of culturally sensitive regulatory principle. ${ }^{15}$ The purpose of such an enterprise is not only to better understand the nature and development of regulatory principle beyond a North World paradigm. It also advances a nexus between social embeddedness and regulatory principle, so that a richer analysis would offer practical opportunities for examining regulatory dimensions within cultures where the state is disaggregated, civil society is resilient, non-government organizations fill many regulatory voids, and multinational commercial incursion is often rapacious. In the case-studies provided later in the book (chapters 5 and 6) we take the contexts of transitional economies and societies as a backdrop to evaluate the dis-embedding tensions in mechanical market economies and the potential of markets to integrate and bond otherwise commercially (and even culturally) unsustainable societies.

\footnotetext{
13 Harvey (2005); Leys (1980).

14 Findlay (2013a).

15 This analytical framework is being tested through empirical research currently funded within Singapore Management University.
} 
With the intention of analyzing market location and social sustainability in mind, some preparatory and prevailing questions include:

1. How are regulatory challenges culturally specific?

2. Are regulatory challenges and regulatory alternatives perceived differently in the South/East and if so, how and why?

3. How does regulation become influenced by mechanical/organic social bonding?

4. Is there a potential to identify significant cultural characteristics which will individualize regulatory policy through social bonding?

5. Why does the language of regulation, when directed towards the South/East World, still focus on the role of the regulatory state?

6. If not as the principal comparative referent, how and why should regulation in the South/East World avoid taking into account the dysfunctional influence of disaggregated states?

The answers to these questions may depend on a range of social and economic assumptions from which we work. Generally put and contestable, for the purposes of our analysis they are proposed as contextual givens, and include that:

- Regulation is fundamentally a question of community/social bonds. Regulation as perceived by any South World society can assist our understanding of regulation as a question of community/social bonds.

- Social bonding is culturally specific. Unlike what has been presumed in contemporary regulatory scholarship, the nature of regulatory principle and project cannot be more cogently appreciated beyond economic and market conditions without a consideration of cultures and related South World contexts.

- Regional and global regulatory crises are currently enunciated from a Western/Northern focus. The subject of regulation policy and commentary itself is a Western conceptualization (or at least viewed from an irredentist perspective) and many of the theories and techniques discussed in regulatory scholarship are building blocks for a theoretical, state-referential model assumed to be superior to, or at least dominant over, those other cultures and societies.

- Contemporary regulatory policy literature is written from a Western/Northern point of view. This historically and commercially prevailing single perspective from which current regulatory scholarship is constructed cannot be said to apply universally or consistently across all cultures if considered from anything but a Western/ 
Northern location, divorced from recognizing degrees of modernization and economic development.

- Regulatory techniques and regulatory theory which influence global and regional policies come primarily from a Western/Northern focus. This dominance stems from the one-time more economically dominant Western hegemony in global affairs, coupled with the cultural insensitivity of global regulation discussed earlier that distorts the eventual determinations of regulatory challenges and their respective solutions. It does not take into account local regulatory needs, responses and principle.

- Regulatory academic and scholarly knowledge are directed towards regulatory challenges in consolidated states. ${ }^{16}$ As a result, small and disaggregated states in the South World that do not conform to governance models to which the Northern states subscribe, are assailed for their unconventional (and even comparatively dysfunctional) governance techniques and policies. Little of the literature from a non-North regulatory origin examines the contribution of post-colonial, or commercially imperial pressures from the North World which add to, or profit from, the disaggregation of South World state institutions and processes.

- Many serious global and regional regulatory problems emerge from post-colonial power and commercially imperial imbalances caused by often predatory multinational influence in developing states. International organizations regularly extort promises of regulatory reform from South World governments in exchange for monetary or other benefits, while multinational conglomerates complicate the dependent domestic investment landscapes and economies in their rush to industrialize.

- Transitional states (economically/politically/culturally and regulatory transitional) are augmenting regulatory alternatives to suit their domestic contexts. Given that these regulatory alternatives are constructed with a Western/Northern focus, they may be incompatible with such domestic contexts, and these transitional states often struggle to keep up with reform as according to contemporary Western regulatory literature.

Along with these contextual considerations run connected critical theoretical assumptions regarding social embeddedness, on which we rely for

16 For a detailed discussion of our use of this notion see Findlay (2013a), chapter 1 . 
the suggested value of organic social bonding as a preferred context for the development of sustainable regulatory principle. Granovetter identifies the 'argument of embeddedness' in these terms: '... that the behavior of institutions to be analyzed are so constrained by ongoing social relations that to construe them as independent is a grievous misunderstanding'. ${ }^{17}$

Granovetter emphasizes the inextricable relationship between institutional behaviour and the forces of social bonding. If the latter, we argue, are organically maintained then institutions and their behaviour will depend for their value on the manner in which they complement and reflect the principles of social bonding. Regulatory principle should be so located.

In order to understand the manner in which the analysis of regulatory principle repositioned from a South World gaze employs social embeddedness, there is a need to discuss our interpretation of how such embeddedness is achieved (or indeed undermined). We will develop these preliminary thoughts more critically in chapter 3 .

\section{MECHANICS OF EMBEDDEDNESS - HOW 'SOLID' IS SOLIDARITY?}

Like regulation, social embeddedness is both a force for and a product of social bonding, or in other words social solidarity. In making this assertion it becomes immediately necessary to seek out and establish a convincing theoretical frame for what we will call the mechanisms of embeddedness. To do this it is useful to explore our particular interpretation of the organic/mechanical dialectic.

In any investigation of the relationships enduring social bonding, external mechanical structural forces can be as influential or more so, than are original bonds of cultural connectiveness. We would accept this assertion particularly in modern North World economic and regulatory arrangements. However, we later argue that as the predominant economic integrative mechanisms move from politically determined distribution in complex stratified societies (where labour, land and capital are commodities) towards those which are rich in socially embedded forms of exchange in small-scale symmetric communities, then the rules of the market are not regulated for in all spheres of human activity, particularly when and where social structures are more redistributive and reciprocal.

17 Granovetter (1985). 
Along with this transformation, social bonding becomes more organic in that it grows out of and relies on socially protective reactions rather than socially distracted structural mechanics. It is what precedes the need for Polanyi's double movement (see chapter 3) as markets are socially supportive rather than dislocated.

Durkheim argued that social order is maintained in societies based on two forms of solidarity: mechanical and organic. ${ }^{18} \mathrm{He}$ proposed that primitive and small-scale societies are typically characterized by mechanical solidarity. It is homogeneity between individuals that allows social order to be maintained - people feeling connected through similar work, education and religious training. In such societies, the structural ties are weak and individuals do not depend on one another to have their needs met. The links between them can be easily broken. For Durkheim, on the other hand, modern and industrial societies are characterized by organic solidarity. Social cohesion comes from the interdependence of individuals on each other in performing different tasks (occupational specialization) and having different values and interests. Because the economic system in particular is one of integrated functions, the ties between individuals are very strong.

Understanding what drives the process of social bonding may be complicated further by its chicken and egg characteristics. Particularly in societies where economies are stratified but fundamental economic relations may still be influenced by organic cultural conventions, mechanical structural forces such as workplace security and hiring conventions (discussed critically in the context of dis-embedded markets in chapter 5) can be critically mediated by organic bonds such as firm loyalty and predictable employment progression. Perhaps a more realistic way of engaging with social bonding is to look at the dynamic influences (organic and mechanical) that move towards or away from embeddedness (Figure 1), and these can work in tension with each other and require resolution with the help of regulatory principle. Our interpretation of the embeddedness/dis-embeddedness dynamic, we later explain (see chapter 3 ), answers the criticism of Polanyi's use of these concepts being too unidirectional and simplistic.

Durkheim accepted that modern society was, at his time, in a transitional phase, demonstrated by an inevitable move from mechanical to organic solidarity with increasing division of labour. In this context social bonds represented through devices such as laws will change a society with mechanical solidarity, transforming through a heavier reliance on

18 Durkheim (1893). 
organic solidarity. In this process of change, laws are reflective of a society's dynamics and rules and regulations are outcomes of people's interactions (discussed critically in chapter 4).

As we will develop later, there is no essential correlation between degrees of market morality and a progression from organic to mechanical solidarity. This is an important observation when in chapter 3 we advance the significance of social embeddedness in determining a realignment of regulatory principle, as some of the more mechanical dimensions of individual wealth creation become subsumed by the risks that fed their profitability. Looking at markets and their behaviour, Durkheim was circumspect as to the satisfactory distinction between organic and mechanical behaviours and relationships. He observed that the rules of supply and demand no longer brought into alignment the moral evaluation of services, remuneration and commodity exchange. Whatever the view of economists, Durkheim suspected that particularly in thinking of differential salary scales, and their exponential growth up the salary chain, for instance, 'lay people felt that it was unfair'. ${ }^{19}$

Turning away from solidarity which holds society together, to reflect on the types of solidarity in social relations - communal and associative 20 - in post-Fordist economies (discussed further in chapter 3), it is apparent that social relationships moulded through the division of labour are no longer universally built on coordinated interests (if they ever were). Associative labour relationships are now more likely to be forced externally and mechanically imposed. Times have changed and where we diverge from Durkheim's treatment of the mechanical/organic dialectic is initially by questioning the contemporary relevance of his version of the division of labour as 'the supreme law of human societies and the condition of their progress'. ${ }^{21}$ Weber would no doubt as an idealized interpretation of the forces behind such a division, favour Durkheim's interpretation that mechanical solidarity constructed through law may constitute imposed devices to control social behaviours and relationships that 'offend(s) strong and defined states of the collective conscience'. ${ }^{22}$ Indeed in post-Fordist capitalist economies we would argue that as a result of the unnatural nature of labour division (and more importantly dis-embedded market arrangements which sustain and are sustained by its artificiality), mechanical rather than organic solidarity prevails due to the recurrent failure of Durkheim's belief in the resilience of meritocracy.

\footnotetext{
19 Durkheim (1897), p. 226

20 Weber (1978 edn), chapter 1.

21 Ibid.

22 Durkheim (1893), p. 39.
} 
A complex division of labour as he saw it meant that people were allocated in society according to merit; therefore moral regulation and economic regulation are needed to maintain order, for people to 'compose their differences peaceably'. ${ }^{23}$ Contrary to this view, in a global setting, the violence entailed in maintaining the post-colonial North/ South economic divide suggests that discriminatory economic ordering requires mechanical enforcement if the oppression of discriminatory peace is to be maintained.

Merit is not an organic discriminator where labour prices are depressed, skill retarded and opportunity constrained in the South for the economic benefit of the North (see our later discussion of the migrant labour market, in chapter 5). Poverty-based discrimination between the world divide questions the real market reasons behind socio-economic developmental failures of South World countries, so often used to justify colonialism. The provident North image suggests that only the systematic adoption of the values, practices, and resources of modernization can overcome the absence of social capital to establish the necessary preconditions for greater material prosperity in the South. ${ }^{24}$ This places a large amount of focus on nation states and transnational corporations, and rational individuals and firms, to lead the South to economic prosperity, while overlooking the vital role of domestic civil society and other institutional arrangements (developed later in chapter 6), appropriately resourced and regulated, that can and should mediate the space between states and markets. In this regard pressures for autonomy (commercial in particular) which feature in North World development models devalue the significance of economic embeddedness, ${ }^{25}$ in favour of atomized markets and autonomous productivity paradigms, mechanically maintained.

We argue that it is this economic and regulatory myopia that ignores the significance of socially embedded economic relations for a South

23 Ibid, p. 60.

24 Woolcock (1998), p. 153.

25 In this chapter, social embeddedness is employed as a critical tool for unlocking the analysis of regulation as a question of community/social bonding. The embeddedness of economic behaviour refers to how economic transactions are embedded in the social relations within that society. The necessary implication is that economic activity is but one category of social activity, and therefore economic growth as the only measure for regulatory effectiveness cannot continue to persist. Through an interrogation of the principle of mechanical/organic solidarity which maintains social order, the organization of social life and social activity takes on a form and meaning that explains legal relationships, or for us, the purposes, and outcomes of regulation. 
world development model likely to avoid the exacerbation of discriminatory mechanical ordering which underpins the North World development dominion. In order to add detail to this revision we engage Granovetter's concepts of embeddedness and autonomy. ${ }^{26}$ In his argument, all economic action is inherently enmeshed in social relations of one configuration or another (with which we agree), and development brought about a change in the kind, not degree of embeddedness. Three claims of this embeddedness thesis demand:

1. All forms of exchange are inherently embedded in social relationships.

2. Embeddedness itself can take several distinct forms - e.g. social ties, cultural practices, and political contexts.

3. Embeddedness within a network can bring benefits as well as costs.

A recurrent theme throughout this book is that to effectively advance a regulatory anthropology employing social embeddedness as an indicator of whether regulatory principle reflects and relies on more organic frames of social bonding the enquiry needs to range across diverse forms of social engagement and not just economy. Locating economy, as we later do (see chapter 3), within more embedded social conditions will enable a measure of the degree of embeddedness and not simply its occurrence, and when sustainability is the regulatory outcome then empirical specificity is even more possible (see chapters 5 and 6). As a dynamic social state it is critical to know how variations in embeddedness influence the transition of regulatory principle, and vice versa. As with the mechanical/ organic dialectic itself, and stages of development, considerations of embeddedness are more transitional than static. In an economic sense this is exemplified in the shift from informal exchange (primitive) to more sophisticated exchange networks (modern). Crucial to any such transition (especially in post-colonial socio-economic frames) is the emergence of new institutional forms, particularly those to guard against corruption and exploitation. As is common in transitional economic and cultural contexts (discussed more fully in chapter 3), these institutions and their positive influence for social embeddedness can be determined through the extent that they are maintained by organic rather than mechanical social bonding. ${ }^{27}$

26 Granovetter (1985), p. 493.

27 Findlay (2007). 
Culturally located social bonding Organic Regulatory social bonding

Social Embeddedness

Principle

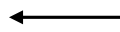

social bonding

Form

Source: author.

\section{Figure 1.1 Social bonding in regulation}

The analysis of regulatory principle in transition, depending on its cultural relevance and location, recognizes that an unyielding emphasis on the consolidated nation state model as a referent for regulation misses the global reality that most societies live within fragmented state frameworks and much of the local regulatory activity in these environments, particularly that emerging out of civil society, is an effort to supplement, sublimate or sustain the state's regulatory failings. ${ }^{28}$ This redirection of analytical focus should not be taken as a venture in pastoral communitarianism which Cohen warns against when particularly examining social control. ${ }^{29}$ We do not suggest that culture-centred principle will always have more regulatory impact or a greater value in motivating regulation than many mechanical regulatory frames (as demonstrated through international conventions and covenants on human rights). To do so would leave us open to a charge of cultural absolutism, ${ }^{30}$ which we eschew. Culture, and relativity to it, is employed here as an analytical device and not as a preferred normative location although with the right social bonding and regulatory conditions, it could be both. As the title of this chapter suggests, whether it is a North or South World cultural context we have a shared interest in fractured spaces in which regulatory principle can have a more sustainable impact. From a perspective of cultural relativity, what this book strives to establish is a positive (in social bonding terms) relationship between principle, organic regulatory forms, and social embeddedness. This enables a critique of regulatory principle and of cultural location in terms of social bonding. Once connected, it is possible at least to interrogate regulatory principle and its transition as forces within and products of social bonding.

Relativity is also a useful approach when searching for the moral relevance of regulatory principles, their relationships and outcomes. In a

\footnotetext{
28 Scherer and Palazzo (2011).

29 Cohen (1985).

30 For a discussion of this notion see Howard (1993).
} 
moral context relativity may neither be culturally nor temporally constrained and a moral lens can temper the essentialism of cultural and contextual analysis when regulation is to be approached as a more universal consideration. Like we will discuss more fully in terms of moral economy, economic and social motivations, relationships, actions and outcomes can be evaluated morally, an approach which is different from the one dominating the prevailing discourse. When such an evaluation is interactive and measured against considerations of embeddedness and sustainability then morality can be both subjective and reflected against uniform considerations of social good, and not profit and individual wealth creation.

\section{SEARCH FOR CULTURALLY LOCATED PRINCIPLE - MORE THAN PROFIT}

Searching for fundamental, culturally grounded regulatory (social bonding) principles might be seen as a celebration of the primacy of popular culture. In an effort to limit any such suggestion this analysis accords with Samir Amin's assertion that 'Culture is a mode of organisation of use values... the direct apprehension of use values, without the intermediary of exchange values... the embryo of a social science based on the dialectic of use value/exchange value... in which commodity exchange performs decisive (although not dominant) functions' ${ }^{31}$

In this sense cultural location is directed specifically at a more embedded context for economy. We are limiting culture for the present to the demonstration and manifestation of values, valuing principles, relationships and outcomes alternative to the dominant economic paradigm. In so doing we could be understood as attacking economic populism in North World materialist valuing. Specifically, market economies in a South World situation are not essentially connected to exchange value. The populism in the South World economic sense is bonded through sustainability more often than through surplus exchange and wealth creation. If this is so, would regulatory motivation and outcomes not also represent a different popular valuing? And how would South World discourse reveal its alternative principled regulatory populism?

Populism as we employ it requires a socially located understanding, whether it concerns regulatory preferencing, or otherwise. With the paucity of an indigenous South World scholarship concerning regulation

31 Amin (1974), p. 190. 
in its own perception, it is necessary, for any subsequent empirical research, also to search for regulatory themes and engagement in literature coming from different disciplines. This is enriching for analysis but has the negative tendency of being hard to locate and to consistently employ understandings arising from any uniform language of analysis. In addition to such empirical challenges there is the more fundamental concern about what narrative reveals the essence of culture? And how does interpretation through external (economic) analysis play a role in understanding that essence?

From as far back as Aristotle, the distinction has been drawn between production for subsistence and production for gain. Achieving production for market exchange, within this distinction, need not destroy selfsufficiency as long as the cash crop would also otherwise have some social embeddedness in subsistence considerations. Amin talked of economic alienation and Karl Polanyi referred to the dis-embedded economy when impersonal market forces and impersonal state technologies for production subordinate man's societal and cultural needs, and not desires. With the growth and significance of disembodied market capital, and the rise of those who have power to profit transnationally, impersonally and without apparent socially embedded consequences, dependent societies in the South World are left to assert protective principles against externally dictated deflation and social disintegration. It is against these principles that our analysis determines its comparative interest, reflecting between the existential polarities which Polanyi identified as:

- Fact and value;

- Empiricism and normativity;

- Society and community; and

- Science and religion.

Polanyi saw these distinctions being 'oscillated as they were tested in life, thought and history'. ${ }^{32}$ Preceding the empirical extension of this analysis, in our consideration of comparisons to follow it is necessary to construe principles as being responses to the regulatory incursions (North to South Worlds or within these worlds), as well as themes for injecting a normative or theoretical reason into regulatory processes and behaviours designed to accord with or enhance social bonding. Fact is essentially

32 Polanyi-Levitt (1990), p. 117. 
informed by value; the normative (principle) directs the empirical (motivation and outcome); economic community recedes back into society; regulatory religion bridges regulatory science through culturally grounded principle. Employing the pathways between such polarities, the empirical researcher then is charged with investigating particular principles, their cultural location, and the forces behind their transition (to influence social bonding) in order to confirm how regulatory principle is revealed through motivations and outcomes not dependent on state referents or North World hegemony.

How would such comparison of principle through harmonizing polarities progress? Grounded enquiry might proceed by turning the comparative exercise to culturally idiosyncratic regulatory paradigms like the Chinese principle of face. Two variants of face exist in the traditional Chinese context: lian and mianzi. Lian means the confidence of society in the integrity and moral character of the particular person, while mianzi refers to a person's reputation achieved through success and ostentation in life. ${ }^{33}$ The loss of face occurs through a violation of the moral order of the society and it brings with it a subjective experience of guilt by the individual who has failed to meet his obligations or by the failure of others to act in accordance with his expectations. ${ }^{34}$

In many East Asian cultural contexts, following and endorsing such norms are core cultural goals that foster group harmony and subscribe to the collectivistic cultural tradition. ${ }^{35}$ The notion of loss of face is not easily grasped as there are a range of situations in which even actions not aimed directly at the individual can cause her a loss of face - for example, a lack of deference shown to friends, relatives or subordinates. We can trace this subjective experience of guilt to the individual bearing some sense of responsibility, and then collectivize the motives and outcomes of the principle of protecting face as an organic regulatory mechanism.

There exists great potential for regulation to grow out of the value accorded to face by Chinese society, particularly in the collective network of social bonds which give value to face and to its maintenance. Recognizing the loss of lian amounts to, and produces, a social sanction in the enforcement of moral standards. ${ }^{36}$ As a result, individuals find themselves, in the course of their transactional exchanges, subject to what is essentially a form of social bonding that alters their behaviour in

\footnotetext{
$33 \mathrm{Hu}$ (1944), p. 45.

34 Ho (1976).

35 Hsu (1948).

36 Bedford and Hwang (2003).
} 
such a way as to conform to the moral standards promulgated by a shared consensus amongst those who they value and respect as comprising the critical hierarchy and authority of their society. The value identified through face empowers a much more influential regulatory principle (control through reputation and shaming) in Asian society than might be claimed by external mechanical regulatory frames such as laws of defamation, because the value of face and the shame from its loss are organic regulators, having grown naturally out of the interactions between critical cultural actors within institutional social bonds such as the family, the workplace, or the local community.

As such, face is an organic regulatory mechanism that particular societies themselves have developed, enunciated and valued/devalued in order to simply, individually and mystically, regulate behaviours that offend a certain set of collectivized moral standards. The motive is individualized, the outcome is collective, and the regulatory principle is embedded in the individual and social psyche.

At the social and cultural level as a regulatory principle, conformity or the unwillingness to cause others to lose face is an important consequent value because conformity and harmony grow out of an active and collective acceptance of the value of the regulatory principle. The existence of such communitarianism means that regulation generates initially from individualized responsibility, and is not imposed from the top, much less from the state. Regulatory principles such as this not only shift the regulatory dialectic away from its current state referent, but precede and exist above and beyond the state. This example of organic regulatory principle clearly breaks any comparative endeavour away from state institutionalism and locates it centrally within networks of deeply traditional social bonding.

The analysis to follow (see chapters 4, 5 and 6) anticipates a more empirical consideration of the relationship between variation in culturecentred principles which underpin social bonding, and intends to reveal the possible connection of socially embedded principle with more organic and embedded, principled regulation. Towards the end of the brief introductory discussion in this chapter we proffer trust as an exemplar of a regulatory principle which has varying regulatory impact depending on its degree of social embeddedness. Trust can be individually focussed, trust in our lives and the lives of others, or in a wider sense of social bonding it is trust in those factors which ensure livelihood; where economy is an essential social relationship and a socialized outcome. 


\section{LIVES AND LIVELIHOOD ${ }^{37}$}

As emphasized above, it is essential not to neglect the cultural context that surrounds and motivates systems for producing goods and services in embedded markets. However, because of the economic ethnocentrism which has infiltrated North World regulatory discourse, this wider cultural lens has not featured in any helpful application of South World experience when interrogating the transition of regulatory principle. The factors that promote or allow such ethnocentrism devalue or even ignore the importance of historically specific analysis of regulation within culture.

All economies - that is, all the material aspects of human cultures involve the provisioning of human purposes by the technological transformation of nature. In all but the most primitive societies, there is also a division of labour with the concomitant necessity of integrative institutions to coordinate economic activity. These institutions have at least superficial similarities - market places, trade, monetary objects, and accounting devices. The presence of these categorical generalities simultaneously makes it fruitful to draw trans-cultural comparisons and establishes the need for methodological discipline so that fundamental and instructive differences are not swept under the rug of hasty generalizations and ethnocentrism. ${ }^{38}$

Market economies are the focus of much North World regulatory discourse. In this section we advance our comparative method (elaborated on more fully in chapter 2) by exploring a little further the distinguishing features of market economies within particular market society conditions. The purpose of this perspective is to appreciate why market economies neither need to nor do stand apart from more encompassing social frames in the South World which determine life well beyond the determinants of economic-only livelihoods. In so doing we need to challenge the prevailing dogma that market culture must legitimate self-gain and subordinate powerful features of traditional obligation, to individualist pecuniary success. For such dogma, social relations are dealt a heavy blow by market economy, and we want to find ways where this need not be so, one being through the differentiation of regulatory principle. For instance, labour force mobility waged against family obligation and located social bonds will create tensions in the measure of life cost/ benefit balance (noted in questions of migrant labour sustainability

37 This juxtaposition is interestingly explored in Stanfield (1990).

38 Stanfield (1990), p. 199. 
canvassed in chapters 5 and 7). The use of economic progress to justify the destruction of historical built environments and established local communities, wildlife habitats, traditional labour skills, and small business foundations of towns and communities, requires critical evaluation (detailed in chapter 6).

In short, the effects of a market economy tend to permeate all aspects of life. Politics, family life, education, the arts, settlement patterns, religion and so on, must comply with, or at least not impede the attitudes and actions necessary for the operation of competitive markets. ${ }^{39}$

Need this be so? In reality, either due to social embeddedness or contesting regulatory principle the same cannot be said of South World economic frames. The pervasive and pernicious impact of market economy modes is a natural consequence of paradoxical market assumptions which substantially question the relevance of the model, such as:

\section{(a) Scarcity and Choice - the Core of Sustainability}

... scarcity of means to satisfy ends of varying importance is an almost ubiquitous condition of human behaviour. ${ }^{40}$

An axiomatic foundation of modern economic science is that decisions about the allocation and distribution of productive capacity will be calculated choices regarding both scarcity and maximization. From Marx's perspective on capitalism's class society, these decisions regarding investments of capital and its timing and direction lie in the hands of the capitalists, that is, those who own all of society's accumulated means of production. It is them who determine which industries or segments of the economic market will expand or decline. ${ }^{41}$ In a similar fashion, if this process is viewed through a Northern ethnocentric lens, then scarcity is dependent on the capacity of the South to fuel the North, where conditions and opportunities for choice are in no way as constrained as those that prevail in the South. The difference here is in the exploitation of embedded economies by the dis-embedded markets of the North. For the vast majority of societies in the South, economy is invisible because economic behaviour is interwoven with the general fabric of social, political and religious life. It would be fair to say in these cultures, economic activity is significantly motivated by social obligation and

\footnotetext{
39 Pearson (1977), p. 12.

40 Robbins (1935), p. 15.

41 Capital, Vol. I, chapter 10, in Tucker (1978), p. 365.
} 
regulated by the moral context that governs social life in general. ${ }^{42}$ In these societies there is no distinct behaviour which is economic by virtue of specific economic motivation or social constraints. Dis-embedded economies, by contrast, became governed by the institutional complex of supply and demand. As a result the distinctly economic motivation and formal rationality for the autonomous sphere of 'economy' became autonomous gain. This leads to a consideration of market economies which trumped all other social motivation through a single-minded emphasis on individualized pecuniary success.

Repositioning regulatory principle as part of the facilitation of social embedding will bring regulation hard up against the formalist axiom, the value prevailing in market societies, that more is better. This value in turn promotes dis-embedded, calculative economy which disrupts collective or mutualized society and stunts individualized social development in the name of mobility, rationality, allocative adjustment, all for the purposes of market efficiency and dislocated productivity.

\section{(b) Market Societies or Markets within Society?}

From a sustainability and communitarian perspective, the economy is an instituted process or culturally patterned arrangement wherein human society sustainably provides for itself. In this vision economic motivation is self-sufficiency in social reproduction, and the substituted instrumentality of the economic process for the life process. Economy, therefore, reasons and is given reason by its specific social embeddedness. The analysis of economic behaviour in this context requires cross-cultural economics, and challenges the ethnocentrism of North World economic modelling, or the a-cultural envisaging of market societies dislocated from any and all societies.

The regulatory framework which sustains embedded economies and markets will approach economic institutions and processes as cultural traits; as expressions of human values stemming from definite patterns of social interaction'. ${ }^{43}$ Moving the consideration of regulatory principle as it imbues economy towards the socially embedded promise of substantivism, will be possible through the empirical examination of South World non-exchange or pre-capitalist economies without being contained within the rigidity of dis-embedded marketing presumptions about universal

\footnotetext{
42 Appleby (1978), chapter 3.

43 Stanfield (1990), p. 204.
} 
economic relations. The interaction of economy and society is a regulatory principle valuing lives above livelihood. Regulation is as such responsible for the subordination of economy to the lives (rather than the markets) it is meant to serve.

\section{(c) Nature as an Object}

A destructive characteristic of North World modernization has been the commodification of all things natural and social. Everything has its price, even life itself. A consequence of universal commodification has been the overemphasis on production and as suggested above the unhealthy fixation on exponential and inevitable economic growth.

Sustainability is forging back into the valuation of economic relationships. The influence of this on motivations for regulation and outcomes is already a feature of North World politics and consumer preferencing. However, this process of recognition is not without pain or economic cost and as such is portrayed as an unnatural reconfiguration of market relationships. Interestingly, by comparison, in economies where commodification has been much more selective and production has not been unbuckled from substantive social interests, sustainability is the natural regulatory principle and as such nature is the context rather than just an expendable object within market transactions.

\section{(d) Primacy of Industrial Production}

Econocentric culture, with its inextricable bonds back to industrialized production, is where meaning is read in a capitalist context from the process of market exchange. The analysis of embedded economy and supportive regulatory principle is a study of social reproduction. Initially then the exploration of embedded economy should proceed from a critical evaluation of North World economic regulatory principle and its impact on specific societies (North and South), polities and cultures when commodity production rather than social reproduction is the paramount motivation and outcome for regulation.

Industry, wage labour and capitalist market arrangements, within regulatory relationships where sufficiency rather than productivity is principled, become processes wherein livelihood facilitates rather than fabricates lives. Once this principled redirection is achieved then considerations of efficiency and productivity no longer value ends over means. The meaning, place and function of human economy are repositioned so that industry is at the service of society and not the other way around. 


\section{(e) Metaphor of Growth}

Development is one of the oldest and most powerful of western ideas. ${ }^{44}$ Central to this perspective is the metaphor of growth. Development is conceived as organic, immanent, directional, cumulative, irreversible and purposive. ${ }^{45}$ Critical to this emphasis was the identification of growth with the modern idea of progress.

In the past, North World socio-economic development has predominantly focused on the economic. Polanyi suggested a new departure for the understanding of growth in socially embedded terms. It offers an alternative definition of economy, another method for economic enquiry, and most important for this chapter, the means to create an alternative standard of value which vests economy (and society) with human meaning. The cursory consideration of central market society characteristics renders a limited opportunity for that exercise. Economic growth developing out of industrial production in which the commodification of nature and society is essential and inevitable will move the market away from its substantive social bonds. This then will create conditions in modernization which require counterpoint if markets are to return to their social roots and thereby gain relevance and resilience. The nature of that counterpoint may be discovered in the stories of regulatory principle and social bonding in cultures where social embeddedness is (or was) not unnatural, not commodified and not subservient to the exponential growth of production.

\section{NEW WAYS OF SEEING REGULATORY PRINCIPLE - PROTECTING SOCIAL EXISTENCE AGAINST MARKET IMPERATIVES}

What Polanyi referred to as an 'obsolete market mentality' is entrenched through economic formalism which represents both the economy and the market as separate from society. In an effort to see what would happen if markets and economies can become socially embedded, or in exploring cultural locations in which socio-economic interaction is given and natural, regulatory principle can be seen as being grounded in and

44 Nisbet (1969), p. 233.

45 Hettne (1990), p. 209. 
reflecting this synergy rather than advancing economic or market paramountcy. Associated with this is an essential need to reconsider economy not only, or simply, in technological or material terms.

So far we have explored the manner in which the cultural location of principle could be understood in terms of organic regulatory forms within socially embedded market conditions, and have identified different priorities and purposes in social bonding as suggesting the nature and impact of such principle. It remains to make some projections on the likely transition of regulatory principle if released from its institutionalization within Northern/Western market economies, and given rein in more organic South World locations and interests. If we see the transformation of regulatory principle in this way as engaging with counterpoint thinking, then how can this transition avoid the criticism that it represents a vague ideological protest against the role of regulation in perpetuating Northern hegemonic economic institutionalism?

To take this further we again borrow from Polanyi's thinking by critically juxtaposing his three modes of economic institutionalization (market exchange, redistribution and reciprocity) in order to envisage different motivations and outcomes for transformed regulatory principle.

In the methodology for engaging with counterpoint we return to the comparative project, but this time using mainstream Northern/Western developmentalist thinking as the referent against which counterpoint can be historically and contextually manifest. While earlier in the chapter we criticized regulatory scholarship constantly reflecting on consolidated states and North World economic paradigms, here we need imagery to counterpoint and in so doing to suggest the possible strengths in the belief systems and cosmology which can spirit a transformation in regulatory principle.

Clearly, it is difficult to comprehend what characterizes one's own society: an outsider has certain advantages of objective perception. Until such times as North-South intellectual relations become more symmetric, and Southern anthropologists flood the Northern metropoles, we have to be content with a few relevant Western contributions that attempt to transcend the Eurocentric tradition and look on Western development 'from outside'. ${ }^{46}$

Some degree of comparative objectivity will help ensure that the consideration of counterpoint is not romanticism, utopian or nostalgic. The populist foundations of counterpoint as we see them in the transformation of regulatory principle may challenge the instrumentalist world

46 Ibid. 
systems and regulatory relationships which confirm Western liberalism. However, as the recent social media mobilization in the Arab Spring disappointments retorts, new methods of populist arrangement are nothing if not culturally located and deeply political.

Market exchange in a populist sense can be understood in different social locations by searching for the threads of economic reciprocity which, in more embedded societies, have a redistributive dimension. Populism in such socially embedded, reciprocal contexts can be seen as:

- Reactions in self-sustaining or embedded market societies to capitalist penetration

- Alliances between organised labour and the small business classes against multi-national colonization

- Small-scale farmer capital fighting against urbanization and finance capital

- Anti-bureaucratic movements in static or fragmented one-time provident states or failed centralized economies.

Populism need not oppose all technological progress or external direct financing, just that which undermines cultural and social embeddedness. However, a problem with populism as a counterpoint to the autonomy of modernized market societies is the claim of 'over-socialization'. Clearly evident in modernized Asian commercial communities, or in those governed by more centralized economies, is the over-socialization of social units such as the family within modernizing economic frames. The significance of consensual values and compliant reaction to authority even in modernized economic environments can tend to confuse simpler measures of embeddedness, wherein its indicators are obscured by concerns about the loss of face and the importance of hierarchies of obligation.

\section{MARKET MYSTICISM}

Before moving on to a consideration of market aphorisms, such as perfect competition, and natural market balance, it is necessary to confront morality. An essential paradox lies in the conventional economics that markets are essentially objective and neutral while at the same time certain market arrangements are good while some are bad. Competition is good, protectionism is bad when in reality oligopolistic cartels in the financial industry are good business. While not wishing to labour the 'good/bad' dichotomy (and its pretence) we consider it important at the outset to align regulatory principle with apparent 
morality in an age where certain economic behaviour is critiqued at least in popular culture as immoral.

To take this course we risk a range of criticisms, not the least of which would focus on the subjectivity and partiality of moral grounding. We counter this by saying that at the very least, in the current problematic discussion concerning the taxpayer's obligation to repay sovereign debt as a moral/democratic obligation, we are invited to critique regulatory austerity in simple moral terms (which will be expanded upon in chapter 4). ${ }^{47}$ Economic morality is a difficult case to put when for centuries the poor have been represented as indolent and the dangerous classes, and the rich through wealth have esteem and respect. However and despite the distortions of popular wisdom it is clear that economies are shaped by moral dispositions and the beliefs demonstrated by the individuals and institutions which govern them as much as they are determined through any objectivist maze of techniques and numbers. ${ }^{48}$ These dispositions emerge from individual and collective political and economic interests and need to be disentangled and responsibilized as such. For instance, enhancing collective moral responsibility in order to collaboratively ensure against risk has been demanded of the banks that till now, some would say, have immorally benefitted through taxpayer bail-outs.

In the North/South economic tension, debt and its ownership stands as a contemporary form of slavery, with more demoralizing consequences than the human enslavement of the South's colonial past. The moral dimension of the slave trade is beyond question. Now global debt is coming under a not dissimilar gaze. Whether contracted individually or impersonally and interpersonally, it is debt as a relationship of power which demands moral engagement, and as such moral motivation in regulatory principle. The rapid divergence in economic trajectories, North to South, have awakened old enslavement and the cruelty of cultural stigma, applied to entire populations, and as in the Eurozone crisis, echoing ghosts of violent pasts.

Aligned with the consideration of economic morality is the counter argument in favour of social atomization. From here, we are told, lies the capacity for the uniquely 'moral' (or at least laudable) market context of perfect competition. The analysis of the paradox of market competition reveals much about the suspect morality of the market and ushers in a revised consideration of regulatory principle.

47 For an interesting consolidation of moral themes regarding economic morality or moral economy see Sayer (2000).

48 Fourcade and Woll (2013), p. 603. 


\section{'SOCIAL ATOMIZATION IS THE PREREQUISITE TO PERFECT COMPETITION'49}

In the under-socialized account of modernization featuring dis-embedded markets, atomization results from the narrow utilitarian pursuit of selfinterest. In the over-socialized account behaviour patterns are internalized and ongoing social relations as a consequence have little more than a peripheral effect on individual behaviour. Reconciling these interpretations in order to reflect on the utility of embeddedness for analyzing regulatory principle requires a return to considering market exchange, redistribution and reciprocity. In so doing we suggest that these variants be employed not so much in functional terms (i.e. what they produce in under or oversocialized settings) but rather against what motivates their attainment. We will take up the challenge of identifying a regulatory principle which separates atomism from embeddedness so as to explain market conditions like exchange, redistribution and reciprocity in either organic (embedded) or mechanical (dis-embedded) terms. The principle is trust (see Figure 1.2).

As the recent public backlash against banker's bonuses in times when the taxpayer was bailing out bank default, it is unconvincing to assume that one's economic interests generally are pursued through gentlemanly means. If competitive forces in a self-regulating market are meant to diminish force or fraud then trust in either that market model or the motivations of its principle players has recently been shattered. Imperfectly competitive markets and the micro-analysis of entrepreneurial motivation have profoundly shaken faith in trust as a market bond when social embeddedness does not feature.

$\begin{array}{lc}\text { Embeddedness } & \text { Dis-embeddedness } \\ \text { General interest } & \text { Self-interest } \\ \text { Generalised Morality } & \text { Malfeasance } \\ \text { TRUST } \longrightarrow \text { TRUST } \\ \text { Organic social bonding }\end{array}$

Source: author.

Figure 1.2 Trust and social bonding

49 Smith (1776), pp. 232-3. 
To paint such a gloomy picture would be to ignore the organizational reality that even in dis-embedded market arrangements much commercial behaviour relies on trust. ${ }^{50}$ From this position we make two fundamental concessions regarding our preferred trust continuum.

1. While trust relationships are present in all market forms they are neither as essential or transparent in dis-embedded market frames; and

2. Trust is a defining organic mechanism for the social bonding indicative of embedded market frames.

Granovetter identifies a distinction between 'functional substitutes for trust' (which in dis-embedded markets could involve external mechanical regulators) and 'concrete personal relations and structures (or networks) generating trust and discouraging malfeasance'.

The widespread preference for transacting with individuals of known reputation implies that few are actually content to rely either on generalised morality or institutional arrangements to guard against trouble ... social relations rather than institutional arrangements or generalised morality are mainly responsible for the production of trust in economic life. ${ }^{51}$

At the same time he accepts that social relations may penetrate irregularly and in different degrees into economic life, and indeed social relations may create conditions for malfeasance which may eventually endanger trust. It is necessary, therefore, as we have suggested earlier, to study patterns of concrete social relations to see when their influence towards embeddedness generates trust or otherwise. Another critical key to exploring the nexus between trust and social relations is to look at how the embeddedness of one significant system such as the market is in turn embedded within broader systems of social relations. One way of doing the latter is to return to our consideration of motive and outcome and ask to what extent is a particular social transaction overlayed by more embedded, dense and long-lasting social relations which bridge different frames of engagement.

If as Mccaulay suggests, 'one doesn't run to lawyers if one wants to stay in business because one must have to behave decently', 52 then it makes sense that this will hold more commonly in certain cultures rather

\footnotetext{
50 Arrow (1974).

51 Granovetter (1985) pp. 490-91.

52 Mccaulay (1963), p. 61.
} 
than others. Granovetter persuasively establishes this point in relation to different cultures of the firm, evidenced through various structural conditions. If the organization of production and labour prefers or is constrained to operate with different structural conditions (determined by (among other factors) social relations) then it follows that cultural conditions, more generally, will influence the proliferation and valuing of trust.

In the regulatory context, the resolution of conflict within particular market frames may influence the importance of trust as a regulatory principle. In this respect a higher order of regulatory influence can be offered to essential market relations, if the market is embedded with social relations which spread beyond the market and into other critical fields of social bonding. Such vertical integration means that conflict within the market can be moderated in terms of other significant and valued market principles going beyond more narrow market imperatives. Cultures providing a more natural vertical integration for market embeddedness may then be able to manage conflict within the market by implicating higher order regulatory principles with more pervasive social value.

\section{CONCLUSION}

Granovetter is right to caution that the 'causal analysis adopted in the embeddedness argument is a rather proximate one'. ${ }^{53}$ Without the benefit of empirical work which interrogates broad historical or macro-structural themes regarding the characteristics which promote or retard embeddedness, one is left begging the question about the connection between culture, social bonding and regulatory principle: what produces the embedding which means that organic regulatory principle evolves more naturally? Granovetter posits that it is the impact of social change on social relations in which economic life is embedded that is a pathway to understanding why particular cultures display the social structural characteristics they have and why these change.

Take for instance the common observation that traditional Chinese family bonding affects the motivation and outcome of wealth creation in modernized societies where Chinese family values predominate, or the conventional Japanese view concerning firm loyalty which may have prior to 'Abenomics' uniquely influenced Japanese firms' recruitment

53 Granovetter (1985), p. 506. 
policies. The regulatory principles behind wealth creation in the earlier instance or employment practice in the latter could not be adequately understood without interrogating the embedding potentials of filial relations or employee/employer loyalty. Certainly in terms of the Japanese example tortuous changes in this underlying principle, determined by demographic and commercial shifts within the Japanese employment environment, has led to transformations in regulatory principle and the strength of social bonds and embedding in modern Japanese social frames.

Weber reminded researchers that economic action should be seen only as a special, if important, category of social action. Accepting this, then both sociological and anthropological interrogations of the place of economy within societies are not only instructive, they are essential. This chapter has advanced both approaches, with the analytical assistance of embeddedness, to suggest that the cultural relativity of social relations has a particular relevance for understanding the economic pre-occupation of modern regulation. If economy is more organically embedded within wider social relations in a particular culture then the principle behind regulating economy will be equally dependent on wider and embedded social relations. 